\title{
AGE OF THE HARRISON STREET BEAST: ELECTRON PARAMAGNETIC RESONANCE SPECTRA FROM TOOTH ENAMEL
}

Robert A. Weeks

Vanderbilt University, Department of Mechanical Engineering

\section{OSTI}

J. Michael Elam

University of Tennessee - Knoxville, Department of Anthropology

James S. Bogard

Oak Ridge National Laboratory, Life Sciences Division

Christian Davenport

University of Tennessee - Knoxville, Department of Anthropology

The submitted manuscript has been
authored by a contract of the U.S.
Government under contract No. DE-
AC05-96OR22464. Accordingly, the
U.S. Government retains a
nonerclusive, royalty-free license to
publish or reproduce the published
form of this contribution, or allow
others to do so for U.S. Government
purposes."

Annual Meeting of the Society for American Archaeology March 25-29, 1998

\author{
Prepared by the \\ Oak Ridge National Laboratory \\ Oak Ridge, Tennessee 37831 \\ Managed by \\ LOCKHEED MARTIN ENERGY RESEARCH CORP. \\ for the \\ U.S. DEPARTMENT OF ENERGY \\ under contract $D E-A C 05-960 R 22464$
}

DISTRIBUTION OF THIS DOCUMENT IS UNLINITED

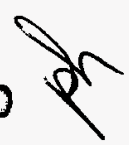

MASTER 


\section{DISCLAIMER}

This report was prepared as an account of work sponsored by an agency of the United States Government. Neither the United States Government nor any agency thereof, nor any of their employees, makes any warranty, express or implied, or assumes any legal liability or responsibility for the accuracy, completeness, or usefulness of any information, apparatus, product, or process disclosed, or represents that its use would not infringe privately owned rights. Reference herein to any specific commercial product, process, or service by trade name, trademark, manufacturer, or otherwise does not necessarily constitute or imply its endorsement, recommendation, or favoring by the United States Government or any agency thereof. The views and opinions of authors expressed herein do not necessarily state or reflect those of the United States Government or any agency thereof. 


\section{AGE OF THE HARRISON STREET BEAST: ELECTRON PARAMAGNETIC RESONANCE SPECTRA FROM TOOTH ENAMEL}

Robert A. Weeks (Vanderbilt University), J. Michael Elam (University of Tennessee - Knoxville), James S. Bogard (Oak Ridge National Laboratory), Christian Davenport (University of Tennessee Knoxville)

\section{Introduction}

Workers doing road reconstruction in 1993 in Ft. Wayne, Indiana, uncovered remains of a large skeleton and contacted archaeologists for assessment prior to continuing work. The archaeologists excavated the remains which were located in a $19-\mathrm{cm}$ thick layer of blue glay, a pedological deposit which forms from wet, anaerobic environments associated with bogs. This glay layer was located some 2 meters below the current ground level (Davenport 1996).

Subsequent morphometric analysis of the skeletal elements clearly suggested that it belonged to the genus Equus or horse. Additional, more extensive analyses indicated that the specimen was probably Pleistocene in age and was probably Equus occidentalis, a now extinct species of horse. Corroborating evidence supporting this conclusion included cut marks on a number of the bones, which are consistent with butchering patterns, and the recovery of Mammut americanum (Mastodon) remains in a similar deposit from a nearby ( $\leq 1$ mile) excavation. Furthermore, microscopic analysis of the cut marks suggests that they were made with stone tools, which implies butchering by prehistoric people (Davenport 1996).

This find, provisionally named the "Harrison Street Beast", is potentially of major archaeological significance. It may represent the only example of direct utilization of the horse by paleoindians, and it is one of very few such specimens recovered from contexts east of the Mississippi river (Davenport 1996). Because of the likely importance of this find, additional confirmation of the results was sought through use of chronometric dating methods. A date obtained by radiocarbon assay (Davenport, 1996; Sample Date no. Beta-80140) of bone collagen extracted from the surviving tibia suggested an age of 101 years. This raises the troubling possibility that the specimen may be modern, when the generally accepted date for the extinction of this species in North America is 11,300 $\pm 1,200 \mathrm{BP}$ (Kurten and Andersen, 1980). In order to resolve this issue, an attempt was made to date some of the molar enamel using electron paramagnetic resonance (EPR).

In this paper, we present the results of an EPR analysis of tooth enamel (biogenic hydroxyapatite) from the Harrison Street Beast. The objectives of this study are: 1) determine an age for the specimen through EPR analysis of molar tooth enamel; 2) resolve and identify the radiationsensitive EPR spectral components; and 3) develop a provisional model for the creation of radiationsensitive components in the EPR spectra.

Grun et al. (1987) have described techniques for using the EPR spectra of tooth enamel to determine the age of a fossil. They show the spectra of the enamel before laboratory irradiation and then with subsequent laboratory irradiations with gamma-ray photons. They analyze the dependence on dose of various parts of the spectral component which they attribute to the enamel, and show that this component is a spin state with $S=1 / 2$ and with approximate axial symmetry, for which 
$g_{\|}=2.0018$ and $g_{\perp}=1.9977$. Jonas (1995) has shown that Grun's component is not a single feature, but that it consists of three components each with $S=1 / 2$, one with axial symmetry and two with g-tensors whose eigenvalues are degenerate. These are $g_{\| 1}=1.99766 \pm 0.00003$ and $g_{\perp}=2.00299 \pm 0.00003$ for the axial site, and $g=2.00184 \pm 0.00034$ and $g=2.0069 \pm 0.0006$ for the other two. (Note that $g_{i}=h \nu / \beta H_{i}$, in which $h, \nu, \beta$ have their customary meaning and the $H_{i}$ 's are the magnetic fields at which peaks in spectral components are observed.) The three components in Jonas' samples gave an A.D. (accumulated dose) which ranged from 105 to $212 \mathrm{~Gy}$.

\section{Methods}

Sample preparation and analytical methods generally followed those suggested by Geyh and Schleicher (1990) and Grun et al. (1987). The details of these procedures are describe in the sections that follow. Samples were prepared by the University of Tennessee - Knoxville, Department of Anthropology. Radioisotopic analyses were performed at the Oak Ridge National Laboratory (ORNL) Dosimetry Applications Research (DOSAR) facility, and added radiation doses were provided at the ORNL Radiation Calibration Laboratory (RADCAL). Electron paramagnetic resonance (EPR) analyses were conducted by laboratories of the ORNL Solid State Division.

\section{Sample Preparation}

A sample of the interior enamel lamellae (Figure 1) was obtained by cutting away the exterior enamel casing with a diamond saw, following recommendations in Grun et al. (1987). Cement and dentine surrounding the interior enamel lamellae were ground away using a Dremel ${ }^{(}$tool fitted with a tungsten-carbide bit. The exterior enamel and a sample of the glay surrounding the skeleton were saved for isotopic analysis.

The interior enamel lamellae were broken into pieces and then hand-powdered in an agate mortar and pestle. The resulting powder was then passed through sieves with $125-\mu \mathrm{m}$ and $98-\mu \mathrm{m}$ openings. Powder that failed to pass through the sieves was re-ground and then re-sieved. This resulted in an enamel powder with grain sizes $s 98 \mu \mathrm{m}$. The powdered enamel was then divided into fractions and each fraction washed in $10 \mathrm{~mL}$ of $10 \% \mathrm{HCl}$ for 15 seconds. This was done to ensure that all remaining dentine and cement was removed. After 15 seconds had elapsed, the remaining $\mathrm{HCl}$ was decanted and the washed enamel rinsed in $100 \mathrm{~mL}$ of deionized, distilled water. The rinsing procedure was repeated five times to ensure that any remaining acid was neutralized. The cleaned enamel fractions were recombined and placed into a crucible and dried in a Transite ${ }^{\circledast}$ oven stabilized at $75^{\circ} \mathrm{C}$ for 24 hours. A total of $5.2 \mathrm{~g}$ of cleaned enamel was obtained and this material was divided into aliquots weighing $100-125 \mathrm{mg}$.

\section{$\underline{\text { Radioisotopic Analysis }}$}

Radioisotope activity concentrations in samples of tooth components and contextual material were determined by gamma-ray spectrometry. Contextual material was analyzed without treatment. Dentine and enamel components of a single tooth were analyzed separately, the enamel in small chunks and the dentine as a powder. The spectrometry system consisted of two p-type germanium 
detectors operating in tandem, coupled for data acquisition to a personal computer through multichannel analyzers and spectroscopic linear amplifiers. The gamma-ray spectra were collected for 72 hours over the energy range $0.05-1.8 \mathrm{MeV}$, and individual radioisotopes were identified using Genie $^{\circ}$ VMS, v. 4.0 (Canberra Nuclear Products), an automated peak-search routine.

\section{Irradiation}

Samples were mounted behind and in direct contact with a $1 / 8$-inch quartz plate which was placed in the centerline of an X-ray beam filtered to produce the M150 beam code defined (Eisenhower, 1984) by the National Institute of Standards and Technology (NIST). The X-ray exposure rate at the sample position was determined by measurement using an ion chamber calibrated by NIST for response to the M150 beam code. The nominal dose (Gy) was determined from the exposure rate $\dot{E}$ $(\mathrm{R} / \mathrm{s})$ and the exposure time $t(\mathrm{~s})$ as $D \approx 0.01 \dot{E} t$, which is the approximate unattenuated dose rate in air. The nominal dose is reported here without correction for photon attenuation by the quartz plate or conversion from exposure (air) to sample dose. Exposure rates were between $185 \mathrm{R} / \mathrm{h}$ and $400 \mathrm{R} / \mathrm{h}$. Samples were contained in small sealable plastic pouches for the early exposures, but were later irradiated inside quartz EPR sample tubes $(4.00 \mathrm{~mm}$ outside diameter, $2.92 \mathrm{~mm}$ inside diameter). Both plastic pouches and quartz tubes containing sample material were mounted behind the quartz plate to assure electronic equilibrium during exposure.

Samples were divided into two groups. Samples in the first group, numbered HB01 through HB06, were given a single acute dose from 10 Gy to 80 Gy over a l-week period, after which ESR analysis was performed. Those in the second group, HB07R (replacement for HB07, which was lost in analysis) through HB12, were provided fractionated doses in 5-Gy to 20-Gy increments over a period of about 3 months. ESR analysis was performed after each subsequent irradiation of the second group. Nominal delivered doses are presented with results of the EPR analysis in Table 1.

\section{EPR Analysis}

In our experiment we evaluated three spectral peaks at $g_{\mathrm{A}}=2.0063, g_{\mathrm{B} / 2}=2.0038$, and $g_{\mathrm{D}}=1.9978$, all with random errors of \pm 0.0003 (when measured on the same spectrum). Because of a systematic error, all g's calculated from measurements of magnetic field and frequency are corrected, based on the $g$ of the $E^{\prime}$ center in silica, by adding 0.0016 to that calculated. All of the samples were prepared from the enamel of the same tooth. Some samples were irradiated with increasing doses, as discussed above, so that we could determine the dose dependence of several individual samples and their intercepts on the amplitude axis. Data for all of the samples were then plotted on a master graph and a linear function fitted to each of the data sets, ' $A$ ', ' $B / 2$ ', and ' $D$ '.

The EPR spectra of our samples were measured at $\sim 9.2 \mathrm{GHz}$, a microwave power of $2 \mathrm{~mW}$, a field modulation frequency of $100 \mathrm{kHz}$, a field modulation amplitude of $0.1 \mathrm{mT}$, and at room temperature. The only spectrometer parameter that we changed was the receiver gain. The amplitudes of the spectral components were normalized to a receiver gain setting of $2 \times 10^{4}$.

EPR sample tubes were filled with the powdered enamel to a height in the tube of $\sim 12 \mathrm{~mm}$. Sample masses were $\sim 100 \mathrm{mg}$. Thus, the cavity filling factors were almost the same and no correction of component amplitudes was made for the filling factor. The method of inserting the 
tubes into the cavity placed the tubes at the same position to within $<0.5 \mathrm{~mm}$ in the vertical direction. The sample position in the horizontal plane was within $0.05 \mathrm{~mm}$. For those measurements in which the signal-to-noise $(\mathrm{S} / \mathrm{N})$ ratio was $>10$, the random errors in our amplitudes were within $10 \%$ of the measured value. For the smaller $\mathrm{S} / \mathrm{N}$ ratios the error increased with decreasing ratio to $\pm 25 \%$ at a ratio of 3 .

The amplitudes of the various EPR spectral components were measured from a baseline that was drawn from one end of the 5-mT sweep to the other for each spectrum. These endpoints were determined by estimating the midpoint of the noise over $0.25 \mathrm{mT}$ at each end of the spectrum.

\section{Results}

Radionuclide activity concentrations determined by gamma-ray spectrometry are shown in Table 2 . The spectrum-analyzing software provides a radionuclide activity estimate and error bounds based on the intensity of each major peak in a particular isotope's spectrum. Sample means of activity concentration for a particular radioisotope were calculated as the average of concentrations reported by the software, weighted for the relative abundances of the photons on which the separate concentrations were based. These concentration means are reported in the table, along with the propagated errors.

Fig. 2 shows the EPR spectrum of an irradiated sample for two magnetic field sweep ranges, one of $0.5 \mathrm{~T}$ and the other of $5 \mathrm{mT}$, centered at $\sim 0.33 \mathrm{~T}$. In the 0.5 - T sweep the most intense components are at $g=4.26 \pm 0.1$ and $g=2$. The $g=4.26$ component is due to $\mathrm{Fe}^{+3}$ (Griscom, 1980). The components at $g=2$ are composed of contributions of $\mathrm{Mn}^{+2}$ (Griscom, 1980); a component whose width is $\sim 60 \mathrm{mT}$ due to aggregations of $\mathrm{Fe}^{+3}$ and $\mathrm{Fe}^{+2}$ (Weeks et al., 1973); a component whose width is greater than the 0.5 -T sweep, also due to aggregations of Fe (Weeks, 1973); and a component at $g=2$ whose width is of the order of $1.5 \mathrm{mT}$ and which is produced by the irradiation, as seen in the portion of the spectrum for which the field sweep was $5 \mathrm{mT}$. We assume that this last component will be indicative of the A.D. of the unirradiated samples of the enamel. We have labeled various parts of this spectrum as ' $A$ ', 'B/2', and ' $D$ '. In those samples which we irradiated in their sample tubes there are paramagnetic components in the spectra from the tube. These overlap part of the ' $\mathrm{B}$ ' component, the larger field part; hence the part free of interference from the tube components was labeled 'B/2'. The tube components are due to E' centers (Weeks, 1956; Weeks and Nelson, 1960; Weeks, 1994). The E' center has $g_{\|}=2.0018$ and $g_{\perp}=2.0006$ at the maximum of the component's absorption (the baseline crossing in the derivative of the absorption spectrum, which is shown in our spectra).

The amplitudes of EPR spectral components and their corresponding nominal doses are summarized in Table 1. The nominal dose appears to be about half the actual delivered dose, based on a preliminary analysis of photon attenuation by the quartz and estimates of effective mass-energy attenuation coefficients for air, quartz, and tooth enamel for exposure to the M150 X-ray beam.

\section{Discussion}

EPR amplitudes of the iron and manganese components did not change, within errors of measurement, for any dose. The numbers of spins contributing to these components are more than 
2 orders of magnitude greater than the radiation-produced components, ' $A$ ', ' $B / 2$ ', and ' $D$ '. We assume that the dose dependencies of the radiation-produced spectral components, shown in the 5-mT sweep of Fig. 2, are independent of the iron and manganese components.

In Fig. 3 we show the spectra of three samples: one without laboratory irradiation, one with a 5-Gy nominal radiation dose, and one with a 10-Gy nominal dose, with spectra of the empty microwave cavity shown in Fig. 4 for comparison. The ' $A$ ', ' $B / 2$ ', and ' $D$ ' parts are resolved in the two irradiated samples, and are not resolved in the unirradiated sample. (There is a spectral feature in unirradiated samples in the same portion of the spectrum as our ' $A$ ', and its contribution is included in the dosimetric regression analysis of ' $A$ ', but its relationship to ' $A$ ' is unclear at this time.) There is a component observed in the unirradiated sample whose peaks are indicated by $g=2.0079$ and $g=2.0055$. Another component is indicated at $g=2.0014$. The $g=2.0055$ appears to be the zero-crossing point of the absorption at $g=2.0079$. The peak occuring at $g=2.0014$ marks a component whose width is much smaller than any other component in the spectrum. Because of its shape and appearance in the three spectra we assign it to a distinct paramagnetic state. A comparison of the spectra of the two irradiated samples shows that this component is not affected by the radiation. With the increasing amplitude of the ' $\mathrm{B} / 2$ ' component with increasing radiation dose and the invariance of the amplitude of this $g=2.0014$ component with dose, it is not resolved in the spectra of samples with larger doses. The amplitude of the part of the component indicated by the $g=2.0079$ peak increases, if it does, with a much slower rate than do the other three parts, ' $A$ ', ' $B / 2$ ', and ' $D$ '. In these samples there is no evidence for an A.D. producing either the ' $B / 2$ ' or ' $D$ ' parts. There may be an indication of an A.D. in the case of the ' $A$ ' part, but this is difficult to assess, since ' $A$ ' is not resolved in the spectrum of the unirradiated sample.

We show in Figs. 5 and 6, in which the data have been fitted with linear functions of dose, that the dose dependencies of the radiation-sensitive spectral components differ. The differences in slopes and intercepts with the amplitude axis are proof that these components are independent and are not different parts of one or two components. Table 3 provides a comparison of the $g$ 's of the various radiation-produced components in enamel observed by Grun, et al. (1987), those deconvoluted by Jonas (1995), and those identified in this work.

The three sets of data agree on one peak with $g=1.9978$ in the powder patterns. We agree with Jonas that there is a peak at $g=2.0037$ and at $g=2.0069$ (within errors of measurement). Because of the interference of the sample tube components, we cannot resolve peaks at $g=2.0018$, except in the spectra of the three samples shown in Fig. 3, as previously discussed. Because of their differing slopes and intercepts, our data do not show that the $g=2.0038$ (our ' $\mathrm{B} / 2$ ') and $g=1.9978$ (our ' $D$ ') peaks are due to a single component, as does the Jonas deconvolution. The ' $B / 2$ ' part continues to a peak on the other side of the baseline which, from its appearance, is part of ' $B / 2$ '; the two parts appear to be an approximately isotropic component. The data of Grun, et al., are consistent with the hypothesis that their $g=2.0018$ and $g=1.9977$ maxima are parts of the same component. There are two other independent components with peaks at $g=2.0037$ and $g=2.0069$, based both on their different dose dependence in our data (our ' $\mathrm{B} / 2$ ' and ' $\mathrm{A}$ ') and on Jonas' deconvolution.

Intercepts, slopes, and regression coefficients are-given in Table 4 for the ensemble of data and for individual samples. Only the ' $A$ ' part has an intercept that may indicate that the sample was exposed in situ, i.e., that it might have an A.D. Linear least-squares regression of the 'B/2' and ' $\mathrm{D}$ ' parts results in a positive intercept of the dose axis. Fitting the curves to a quadratic function, as in 
Fig. 7, provides a slightly better fit of the data, is visually more gratifying, and results in intercepts at or near the origin for the ' $B / 2$ ' and ' $D$ ' components. Supralinearity at low doses, such as that implied by Fig. 7, is also observed in thermoluminescence analysis of natural materials and has not been satisfactorily explained (Mejdahl and Wintle, 1984).

In the production of paramagnetic states by electron (hole) capture at some site in the material, there must also be a hole (electron) trapped at some other site. Absorbed radiation, in the simplest model of radiation effects, excites an electron from the valence band of a wide-band-gap material (such as tooth enamel) to the conduction band. The electron then moves through the material until it is captured by a site which has a binding energy to trap the electron for a time sufficient for it to be observed in our measurements. In the case of tooth enamel this time may be millions of years. The site from which the electron is excited is a 'hole', which can also move through the material until it also is trapped. Both the electron traps and the hole traps have energies that, in many cases, are both between the energies of the valence and conduction bands and are paramagnetic. The spectral components we observe in our experiments are clearly not due to the presence of trapped-electron/trapped-hole pairs, but belong to either trapped electrons or trapped holes because of the differing dependencies on dose.

If we assume that all of these components are due to trapped holes, then there is the question of the sites at which the electrons are trapped. In wide-band-gap materials in which both $\mathrm{Fe}^{2+}$ and $\mathrm{Fe}^{3+}$ are present it is possible to change the +3 state to the +2 state by capturing an electron. Thus the presence of $\mathrm{Fe}$ in our samples may provide trapping sites for electrons. The change in the number of $\mathrm{Fe}^{3+}$ ions would be a small fraction $(<0.01)$ of the available $\mathrm{Fe}^{3+}$ ions, since the number of $\mathrm{Fe}$ ions contributing to the $g=4.26$ component (not even considering the contribution due to Fe-ion aggregates) is more than 2 orders of magnitude (as shown in Fig. 2) greater than the number of radiation produced sites (' $A$ ', ' $B / 2$ ', and ' $D$ '). Thus, a change in the amplitude of the $g=4.26$ component due to combination with radiation-generated electrons would not be detected.

The g's of various components observed by Grun, et al., Jonas, and in our work are shown in Table 3. From this table we see that Jonas identifies an isotropic component, G2, with the same $g$ as our ' $\mathrm{A}$ ' part. We also note that the $g_{+}$of his ' $\mathrm{A}$ ' component is, within the errors of measurement, the same as our ' $\mathrm{B} / 2$ ' part. We are all in agreement with respect to the $g_{1}$ defined by Grun, et al., Jonas, and our ' $D$ ' part. However, our data on the ' $B / 2$ ' and ' $D$ ' parts of our spectra are consistent with a hypothesis that these two parts are independent paramagnetic states, while Jonas indicates that these are a single axially symmetric paramagnetic state.

Activity concentrations of radioactive elements present in the soil, enamel pieces, and dentine powder, given in Table 2, show that the naturally occurring series of ${ }^{232} \mathrm{Th}$ and ${ }^{238} \mathrm{U}$ are present in the soil and that the parent nuclides appear to be in approximate secular equilibrium with their progeny, including those from ${ }^{220} \mathrm{Rn}$ and ${ }^{222} \mathrm{Rn}$. This conclusion is based on the relative abundances of ${ }^{228} \mathrm{Ac}$ and ${ }^{208} \mathrm{Tl}$ in the ${ }^{232} \mathrm{Th}$ series, and of ${ }^{234} \mathrm{Th},{ }^{214} \mathrm{~Pb}$, and ${ }^{214} \mathrm{Bi}$ in the ${ }^{238} \mathrm{U}$ series. (The parent ${ }^{232} \mathrm{Th}$ and ${ }^{238} \mathrm{U}$ were not quantifiable at these levels because of interference from actinidic contamination of the materials used in fabrication of the detectors.) It is evident from these data that the diffusion of radioactive elements into the enamel has been small,-resulting in concentrations in the interior enamel that are only around $10 \%$ of those in the glay. Dose rate conversion factors from Mejdahl and Wintle (1984), shown in Table 5, were used with the observed radionuclide concentrations to estimate environmental effective dose rates to the enamel. An EPR efficiency of 0.15 was assumed 
for $\alpha$ particles, based on reported efficiencies for $\alpha$-produced thermoluminescence. Different assumptions about contributions from $\alpha=, \beta$-, and $\gamma$-dose components were used to generate estimates of the lowest, highest, and most probable total environmental dose rates, which are found in Table 6. The lowest-dose-rate estimate assumes that, considering the large uncertainties in enamel radionuclide concentrations, the observed concentrations are not significantly different from zero (which is strictly true within the $95 \%$ confidence interval for ${ }^{40} \mathrm{~K}$ and for radioisotopes in the ${ }^{232} \mathrm{Th}$ series). Environmental radiation dose is due solely to $\gamma$ irradiation from the surrounding soil in this scenario, and the lowest reported values for radionuclides in the soil are used in arriving at a dose estimate of $1,227 \mu \mathrm{Gy} / \mathrm{a}$. The highest-dose-rate estimate uses the highest reported radionuclide concentrations in soil and enamel and assumes a rapid equilibration of radionuclides in the enamel, resulting in an estimated $1,763-\mu \mathrm{Gy} / \mathrm{a}$ dose rate. The most probable effective dose rate was derived using the mean of lowest and highest reported activity concentrations. This value was halved to estimate average concentrations in interior enamel, accounting for time required for diffusion from soil to teeth. The most probable environmental effective dose rate is $1,763 \mu \mathrm{Gy} / \mathrm{a}$.

An upper bound on the age of the Harrison Street Beast is found from an estimate of our critical level (the level below which an EPR signal is assumed to be not different from background, within the $95 \%$ confidence interval of background measurement results) and the environmental effective dose rate. We report a $25 \%$ uncertainty ( $1 \sigma$ confidence interval) in the EPR result from sample HB07R with a nominal delivered dose of $5 \mathrm{~Gy}$ (actual dose of about $10 \mathrm{~Gy}$ ). This corresponds to a critical level of about $5 \mathrm{~Gy}$, actual delivered dose. The maximum age of the Harrison Street Beast, based on the EPR analysis, is then 2,800 - 4,100 y, with a most probable maximum age of $3,400 \mathrm{y}$.

\section{Conclusions}

We conclude that the enamel from the teeth of the Harrison Street Beast has an age that is less than $4,100 \mathrm{y}$, and is more probably less than 3,400 y. Potassium and uranium/thorium series concentrations were only about $10 \%$ of those observed in the surrounding soil, which is to be expected for a relatively young specimen. [Migration of uranium in enamel, for instance, is on the order of $1-3 \mathrm{~cm}$ in 100,000 years (Grun et al., 1987)].

The fact that both radiocarbon analysis and our results indicated that the specimen may be recent raises significant issues. Radiocarbon dates based on bone collagen are often unreliable (Bowman, 1990; Geyh and Schleicher, 1990) and the accuracy of EPR dates are affected by the accumulated radiation dose, which can depend significantly on uptake of contextual radionuclides. Nevertheless, the corroborating EPR and radioisotopic evidence (both bone collagen ${ }^{14} \mathrm{C}$ analysis and gamma-ray spectrometry of tooth and contextual materials) suggests that the specimen may be much younger than originally believed. Therefore, a radiocarbon date based on intact amino acids, and perhaps a reevaluation of the archaeological data, would be useful. In particular, reexamination of the morphology of these skeletal remains is strongly suggested.

It is evident from a comparison of our data with those of Grun $e t$ al. and Jonas that there is only limited agreement on the EPR components produced by irradiation of the enamel of the various specimens that have been investigated. We clearly show at least 3 independent paramagnetic components, based on the unique radiation dependence of our ' $A$ ', ' $B / 2$ ', and ' $D$ ' spectral features. 
Our ' $\mathrm{D}$ ' component at 1.9978 corresponds with the $g \|$ of both Jonas and Grun, et al. We also find a peak at 2.0063 (our ' $A$ ') that corresponds with Jonas' 'G2', and one at 2.0038 that corresponds with Jonas' 2.0029 (within errors of measurement), but which have no correspondence with any of the features reported by Grun et al. Both Grun et al. and Jonas suggest that the feature at 1.9974 should change with irradiation with the same dependence as either that at 2.0029 (Jonas and this work) or 2.0018 (Grun, , et al.), but our results indicate that this is not the case. Additional research is clearly needed to resolve the EPR spectral components of tooth enamel and their dependence on enamel composition.

There is not sufficient information at this time to present a fully developed model for the production of EPR features by irradiation. We suggest that the presence of $\mathrm{Fe}$ ions in the enamel provides a possible mechanism for trapping electrons, which would leave behind unpaired holes and give rise to the observed EPR spectra. The reduction of $\mathrm{Fe}^{3+}$ to $\mathrm{Fe}^{2+}$, which would trap electrons and leave unpaired holes, should be reversible by thermal treatment and would result in the disappearance of the EPR features under such conditions. Oxidation of $\mathrm{Fe}^{2+}$ under these conditions would free the trapped electrons, allowing them to migrate in the enamel matrix and neutralize the unpaired holes. This proposed model, although provisional, can be tested and refined with additional appropriately designed experiments.

A degree of supralinearity in the radiation dependence of EPR spectral features is implied by the good quadratic fit of Fig. 7. Some supralinearity is expected, to the extent that EPR results mimic those of thermoluminescence; however, supralinearity gives way to linearity after fewer than 5 Gy of added dose in thermoluminescence results (Mejdahl and Wintle, 1984). Supralinearity is not well understood, and these observations indicate that the phenomenon may be a significant factor in correctly interpreting EPR data and should be studied further.

\section{References}

Baker, 1972

G. J. Baker, "Surgery of the Head and Neck," p. 761 in Equine Medicine and Surgery, eds. E. J. Catcott and J. F. Smithcors, American Veterinary Publications, Inc., Wheaton, Illinois (1972)

Bowman, 1990

Sheridan Bowman, Radiocarbon Dating, University of California Press, Berkeley, California, pp. 29-30 (1990)

Davenport, 1996

Christian Davenport, "The Harrison Street Beast," Contract report prepared for the Division of Archaeology, Indiana University Purdue University at Ft. Wayne, Indiana, $26 \mathrm{pp}$. (1996)

Eisenhower, 1984

E. H. Eisenhower, "Quality assurance for measurements of ionizing radiation," NUREG/CR-3375, National Bureau of Standards, Washington, D.C. (1984) 
Geyh and Schleicher, 1990

Griscom, 1980

Grun et al., 1987

Mejdahl and Wintle, 1984

Jonas, 1995

Kurten and Andersen, 1980

Weeks, 1956

Weeks and Nelson, 1960

Weeks, 1973

Weeks, 1994

Weltner, 1983
M. A. Geyh and H. Schleicher, Absolute Age Determination, Springer-Verlag, Berlin (1990)

Dave Griscom, "Part II, Magnetic properties; electron spin resonance in glasses," J. Non-Cryst. Solids, 40, 211-272 (1980)

Ranier Grun, Henry P. Schwarz, and Steve Zymela, "Electron spin resonance dating of tooth enamel", Can. J. Earth Sci., 24, 1022-1037 (1987)

V. Mejdahl and A. G. Wintle, "Thermoluminescence applied to age determination in archaeology and geology," pp. 133190 in Thermoluminescence and Thermoluminescent Dosimetry. Volume III, ed. Yigal S. Horowitz, CRC Press, Inc., Boca Raton, Florida (1984)

Martin Jonas, "Spectral deconvolution of the ESR dating signal in fossil tooth enamel," Quat. Sci. Rev.(Quat. Geochronolgy), 14, 431-8 (1995)

B. Kurten and E. Anderson, Pleistocene Mammals of North America, Columbia University Press, Guildford, Surrey (1980)

R. A. Weeks, "Paramagnetic resonance of lattice defects in quartz," J. App. Phy., 27, 1376-1381 (1956)

R. A. Weeks and C. M. Nelson, "Trapped electrons in quartz and silica: Electron spin resonance," J. Am. Cer. Soc., 43, 399-404 (1960)

R. A. Weeks, "Ferrimagnetic phases in lunar fines and breccias: Electron magnetic resonance spectra of Apollo 16 samples," Geochem. et Cosmochem. Acta, Supp. 4, 3, 27632781 (1973)

R. A. Weeks, "The many varieties of the E' center: A review," J. Non-Cryst. Solids, 179, 1-9 (1994)

William Weltner Jr., Magnetic Atoms and Molecules, Scientific and Academic Editions, Van Nostrand Reinhild 
Co., Inc., New York, 385 (1983) 
Table 1. Nominal Delivered Doses ${ }^{1}$ and Corresponding Amplitudes of EPR Spectral Components

\begin{tabular}{cccccc} 
& & & \multicolumn{3}{c}{ Mass-Normalized Response $\left(\mathrm{mg}^{-1}\right)$} \\
\cline { 5 - 6 } Sample & Mass & Dose & & & \\
No. & $(\mathrm{mg})$ & Gy $)$ & 'A' & 'B/2' & 'D' \\
\hline PH02 & 111.9 & 0 & 0.0223 & 0.0000 & 0.0000 \\
HB01 & 90 & 10 & 0.0278 & 0.0444 & 0.0389 \\
HB02 & 90 & 20 & 0.0389 & 0.100 & 0.0556 \\
HB03 & 70 & 35 & 0.0500 & 0.143 & 0.0857 \\
HB04 & 160 & 50 & 0.0375 & 0.181 & 0.112 \\
HB05 & 120 & 65 & 0.0667 & 0.308 & 0.200 \\
HB06 & 110 & 80 & 0.0727 & 0.400 & 0.254 \\
& & & & & \\
HB07R & 117.5 & 5 & 0.0136 & 0.0272 & 0.0068 \\
HB08 & 125 & 15 & 0.0200 & 0.0600 & 0.0400 \\
HB09 & 127 & 30 & 0.0394 & 0.118 & 0.0787 \\
HB10 & 128 & 30 & 0.0391 & 0.117 & 0.0781 \\
HB11 & 98 & 45 & 0.0510 & 0.214 & 0.122 \\
HB12 & 75 & 45 & 0.0533 & 0.160 & 0.107 \\
HB07R & 117.5 & 15 & 0.0213 & 0.0553 & 0.0383 \\
HB08 & 125 & 25 & 0.0320 & 0.112 & 0.0800 \\
HB09 & 127 & 60 & 0.0787 & 0.268 & 0.158 \\
HB10 & 128 & 60 & 0.0625 & 0.266 & 0.188 \\
HB11 & 98 & 75 & 0.102 & 0.408 & 0.245 \\
HB12 & 75 & 75 & 0.0800 & 0.400 & 0.267 \\
HB07R & 117.5 & 25 & 0.0383 & 0.102 & 0.0511 \\
HB08 & 125 & 35 & 0.0480 & 0.160 & 0.0960 \\
HB09 & 127 & 90 & 0.0945 & 0.409 & 0.268 \\
HB10 & 128 & 90 & 0.0938 & 0.406 & 0.266 \\
HB11 & 98 & 105 & 0.122 & 0.582 & 0.357 \\
HB12 & 75 & 105 & 0.107 & 0.560 & 0.373
\end{tabular}

'Actual delivered doses to enamel are approximately twice the reported nominal doses. 
'paนodas pou a.te 'suo!je.1

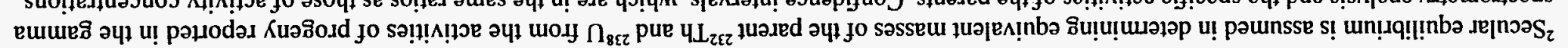

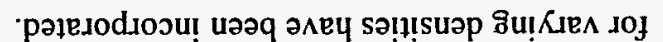

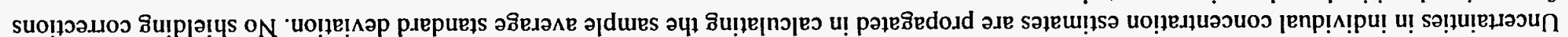
uoljeı

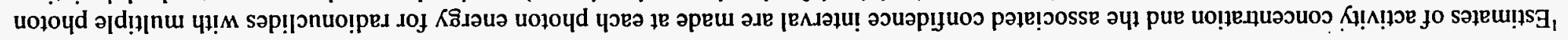

\begin{tabular}{|c|c|c|c|c|c|c|c|}
\hline IS 0 & sto & $06 \varepsilon$ & & $9 \mathrm{I}^{\circ} 0 \mp \angle \mathrm{I}^{\circ} 0$ & $6 E^{\circ} 0 \mp 9 I^{\circ} 0$ & $60^{\circ} 0 \mp \mid \varepsilon I$ & $! \mathrm{g}_{t 12}$ \\
\hline $6 \varepsilon^{\circ} 0$ & 890 & $06^{\circ} \varepsilon$ & $\bigcap_{8 \varepsilon \tau}$ & $900 \mp \varepsilon[0$ & $8 E I \mp \varepsilon Z 0$ & $\left.60^{\circ} 0 \mp I \varepsilon\right\rfloor$ & $9 d_{t 12}$ \\
\hline- & - & $90^{\circ} \mathrm{S}$ & & $-\ldots$ & -- & $9 \varsigma 0 \mp 0 L 1$ & $4 \iota_{b \varepsilon z}$ \\
\hline$\angle 20$ & $\dagger \varepsilon$ & $\varsigma 9$ & \multirow{2}{*}{ บ. $\mathrm{L}_{z \varepsilon z}$} & แ & $0 S^{\circ} 0 \mp \angle E^{\circ} 0$ & $\angle 0^{\circ} 0 \mp 1 \angle 0$ & $1 \mathrm{~L}_{80 \tau}$ \\
\hline$\$ 90$ & $9: 1$ & $0 L$ & & $110 F \angle 0^{\circ} 0$ & $08^{\circ} 0 \mp \angle 1 I^{\circ} 0$ & $E O^{\circ} 0 \mp \angle L O$ & $O \forall_{8 Z 2}$ \\
\hline$\therefore$ & $80^{\circ} 0$ & $6 I^{\circ} z$ & $\left(X_{0 t}\right)$ & -- & $\varepsilon Z^{\circ} \succsim \mp 6 \varsigma^{\bullet} 0$ & $0 Z^{\prime} I \mp \emptyset \varepsilon S I$ & $X_{0 t}$ \\
\hline 1GWVNG & GNILNGA & TIOS & $\begin{array}{l}\text { sə!ıəS } \\
\text { КвวəД }\end{array}$ & TaWVNG & ヨNILNGם & TIOS & әp![วnuo!pey \\
\hline
\end{tabular}

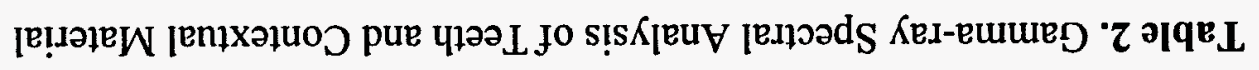


Table 3. $g$ 's of Radiation-Produced Components in EPR Spectra of Horse Tooth Enamel

\begin{tabular}{lllcc} 
& & & $g_{\perp}$ & $g_{1}$ \\
\cline { 3 - 5 } Grun, et al. (1987) & & & 2.0018 & 1.9977 \\
Jonas (1995) & & & & \\
& A & & 2.0029 & 1.9977 \\
& G1 & 2.0018 & & \\
& G2 & 2.0069 & &
\end{tabular}

This Paper
A 2.0063
$\mathrm{B} / 2 \quad 2.0038$
D $\quad 1.9978$

Weltner (1983)

$\mathrm{CO}_{3}^{-}$

$2.00312 .0013 \quad \mathrm{In}^{\mathrm{CaCO}_{3}}$

$2.0083 \quad 2.0065 \quad$ In $\mathrm{KHCO}_{3}$ 
Table 4. Slopes ${ }^{1}$ and Intercepts ${ }^{1}$ for Individual Samples and Ensembles

\begin{tabular}{|c|c|c|c|c|c|c|c|}
\hline \multirow[b]{2}{*}{ Sample No. } & \multirow[b]{2}{*}{$\begin{array}{c}\text { Nominal } \\
\text { Dose }^{\prime} \\
\text { Range (Gy) }\end{array}$} & \multicolumn{2}{|c|}{ EPR 'A' } & \multicolumn{2}{|c|}{ EPR 'B/2' } & \multicolumn{2}{|c|}{ EPR 'D' } \\
\hline & & $\begin{array}{c}\text { Slope } \\
\left(\mathrm{mg}^{-1} \mathrm{~Gy}^{-1}\right) \\
\left(\times 10^{3}\right)\end{array}$ & $\begin{array}{c}y \text {-Int } \\
\left(\mathrm{mg}^{-1}\right) \\
\left(\times 10^{3}\right)\end{array}$ & $\begin{array}{c}\text { Slope } \\
\left(\mathrm{mg}^{-1} \mathrm{~Gy}^{-1}\right) \\
\left(\times 10^{3}\right)\end{array}$ & $\begin{array}{c}y \text {-Int } \\
\left(\mathrm{mg}^{-1}\right)\end{array}$ & $\begin{array}{c}\text { Slope } \\
\left(\mathrm{mg}^{-1} \mathrm{~Gy}^{-1}\right) \\
\left(\times 10^{3}\right)\end{array}$ & $\begin{array}{c}\begin{array}{c}y \text {-Int } \\
\left(\mathrm{mg}^{-1}\right)\end{array} \\
\left(\times 10^{3}\right)\end{array}$ \\
\hline HB07R & $5-25$ & 1.2 & 6 & 3.7 & 5 & 2.2 & -1 \\
\hline HB08 & $15-35$ & 1.4 & -2 & 5.0 & -14 & 2.8 & 2 \\
\hline HB09 & $30-90$ & 0.92 & 16 & 4.9 & -26 & 3.2 & -21 \\
\hline HB10 & $30-90$ & 0.91 & 10 & 4.8 & -26 & 3.1 & -10 \\
\hline HB11 & $45-105$ & 1.2 & 3 & 6.1 & -58 & 3.9 & -52 \\
\hline $\mathrm{HB12}$ & $45-105$ & 0.89 & 13 & 6.7 & -127 & 4.4 & -84 \\
\hline $\begin{array}{l}\text { PH002, } \\
\text { HB01-HB06 }\end{array}$ & $0-80$ & \multicolumn{2}{|c|}{$\mathrm{r}^{2}=0.85$} & \multicolumn{2}{|c|}{$r^{2}=0.97$} & \multicolumn{2}{|c|}{$r^{2}=0.96$} \\
\hline All Samples & $0-105$ & \multicolumn{2}{|c|}{$\mathrm{r}^{2}=0.92$} & $\begin{array}{l}5.3 \\
r^{2}=0\end{array}$ & -26 & $\begin{array}{l}3.4 \\
r^{2}=\end{array}$ & $7^{-19}$ \\
\hline
\end{tabular}

'Nominal doses are reported; slopes and intercepts were derived using the nominal doses. Actual delivered doses are approximately twice the nominal doses. 
Table 5. Dose rate conversion values for the naturally ocurring radionuclides (adapted from Mejdahl and Wintle, 1984)

\begin{tabular}{lcccc} 
& & \multicolumn{3}{c}{ Dose Rate $(\mu \mathrm{Gy} / \mathrm{a})$} \\
\cline { 3 - 5 } Radionuclide & Concentration & $\alpha$ & $\beta$ & $\gamma$ \\
\hline $\begin{array}{l}\text { Thorium series } \\
\text { (No thoron loss) }\end{array}$ & $1 \mathrm{ppm}^{232} \mathrm{Th}$ & 738 & 28.6 & 51.4 \\
$\begin{array}{l}\text { Uranium series } \\
\text { (No radon loss) }\end{array}$ & $1 \mathrm{ppm}^{238} \mathrm{U}$ & 2,783 & 146.2 & 114.8 \\
Natural Potassium ${ }^{1}$ & $1 \mathrm{ppm}^{40} \mathrm{~K}$ & & 697.7 & 203 \\
& & & & \\
& \\
& \\
'Based on Mejdahl and Wintle's values for $1 \%$ natural potassium; \\
$1 \% \mathrm{~K}_{\text {nat }}=1.19 \mathrm{ppm}^{40} \mathrm{~K}$.
\end{tabular}


Table 6. Effective dose rate to interior tooth enamel of the Harrison Street Beast

\begin{tabular}{ll}
\multicolumn{3}{c}{ Effective $^{1}$ Dose Rate } \\
$(\mu$ Gy/a $)$
\end{tabular}

$\gamma$ (from soil)

$\begin{array}{llll}{ }^{40} \mathrm{~K} & 445 & 445 & 445 \\ { }^{232} \mathrm{Th} & 334 & 347 & 360 \\ { }^{238} \mathrm{U} & 448 & 514 & 581\end{array}$

$\beta$ (from interior enamel)

$\begin{array}{cccc}{ }^{40} \mathrm{~K} & - & -- & -- \\ { }^{232} \mathrm{Th} & 0 & 3 & 18 \\ { }^{238} \mathrm{U} & 0 & 33 & 75\end{array}$

$\alpha$ (from interior enamel)

$\begin{array}{cccc}{ }^{232} \mathrm{Th} & 0 & 25 & 71 \\ { }^{238} \mathrm{U} & 0 & 94 & 213\end{array}$

$\begin{array}{llll}\text { TOTAL } & 1,227 & 1,461 & 1,763\end{array}$

'An EPR efficiency of 0.15 is applied to the $\alpha$ dose, with the assumption that $\alpha$-particle efficiency in producing EPR signal is the same as for producing thermoluminescence (Mejdahl and Wintle, 1984).

${ }^{2}$ Assumes that reported activity concentrations in enamel are not different from zero (negligible $\alpha$ and $\beta$ irradiation from radionuclides in the enamel); all dose is presumed due to $\gamma$ radiation from soil. Values for $\gamma$-emitters in soil are the lowest reported.

${ }^{3}$ Assumes that an intermediate value between the lowest and highest reported
represents the best estimate of current radionuclide concentration. Half this
intermediate value is taken to be the mean concentration in the interior enamel,
averaged from time zero to the present.

${ }^{4}$ Assumes the highest values reported. Values for $\alpha$ - and $\beta$-irradiation assume that activity concentrations from Table 2 equilibrated rapidly in the enamel. 


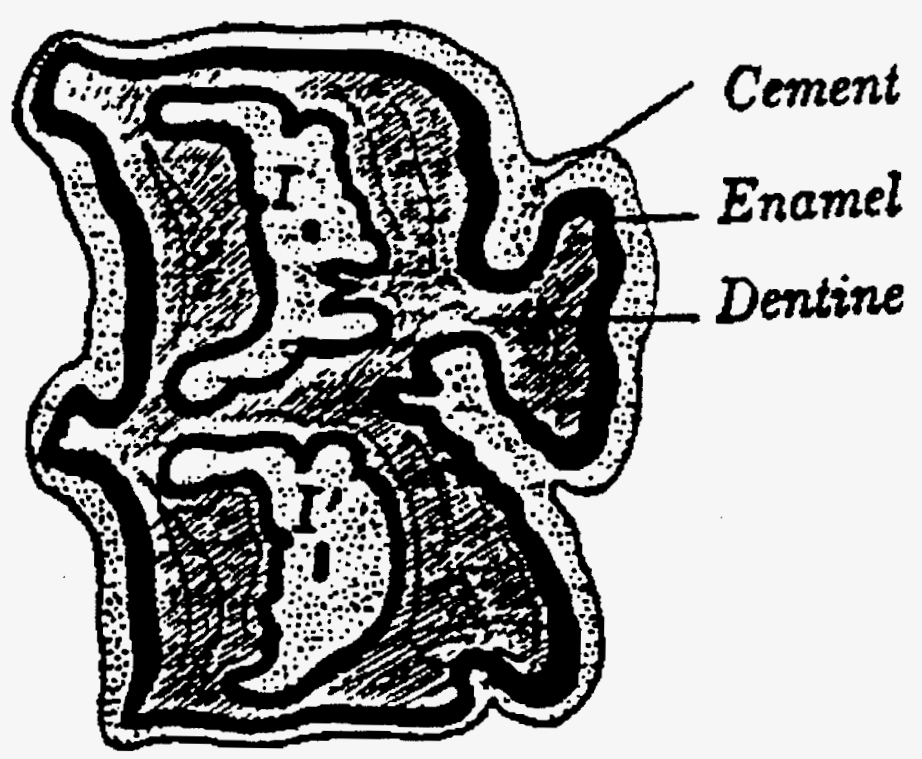

Figure 1. Interior structure of a horse maxillary molar. The cement is denoted by $I$ and $I^{\prime}$. Interior enamel used in this study is denoted by the heavy black areas surrounding the cement. (Figure taken from Baker, 1972.) 
First Derivative of Absorption

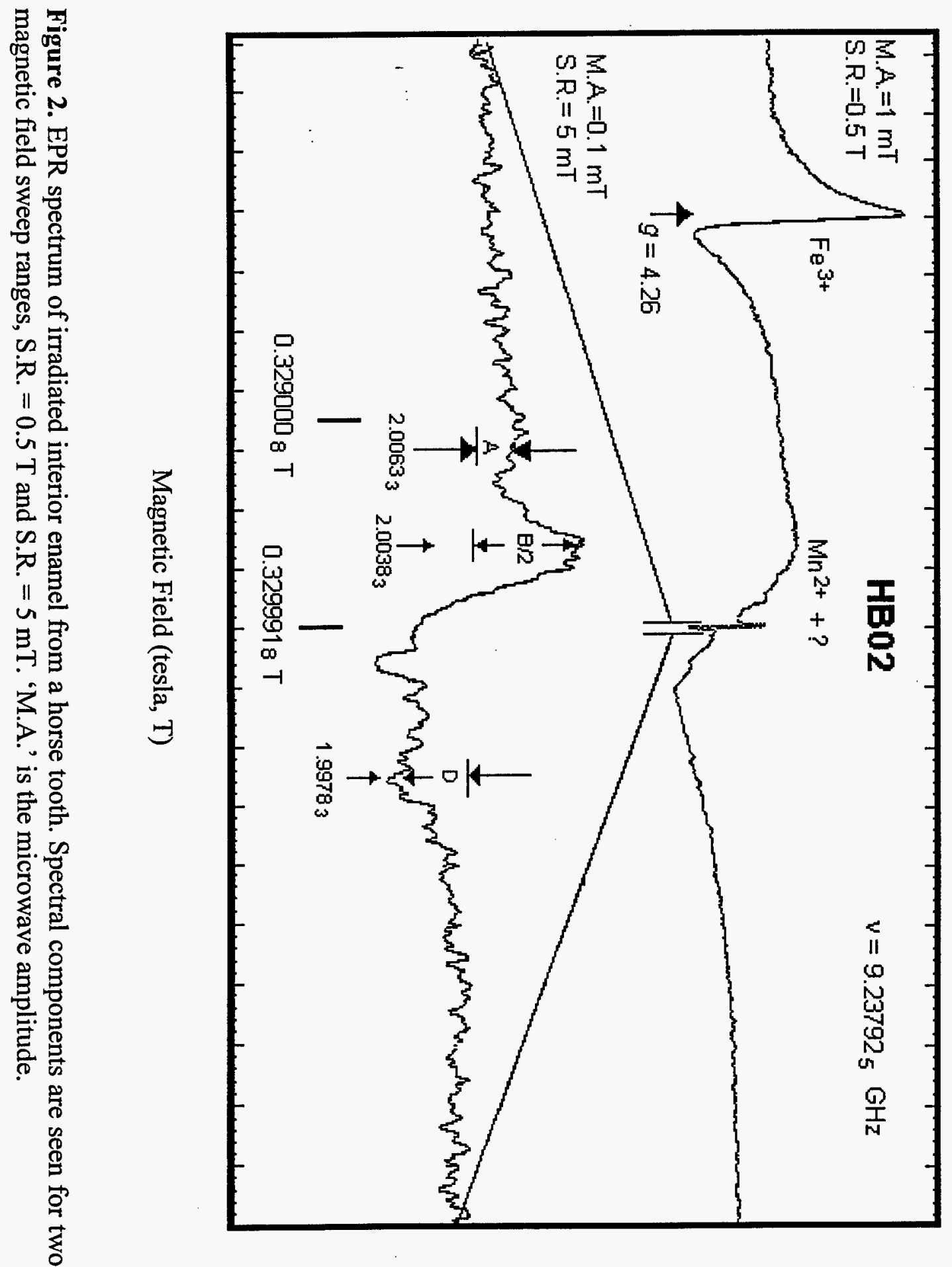




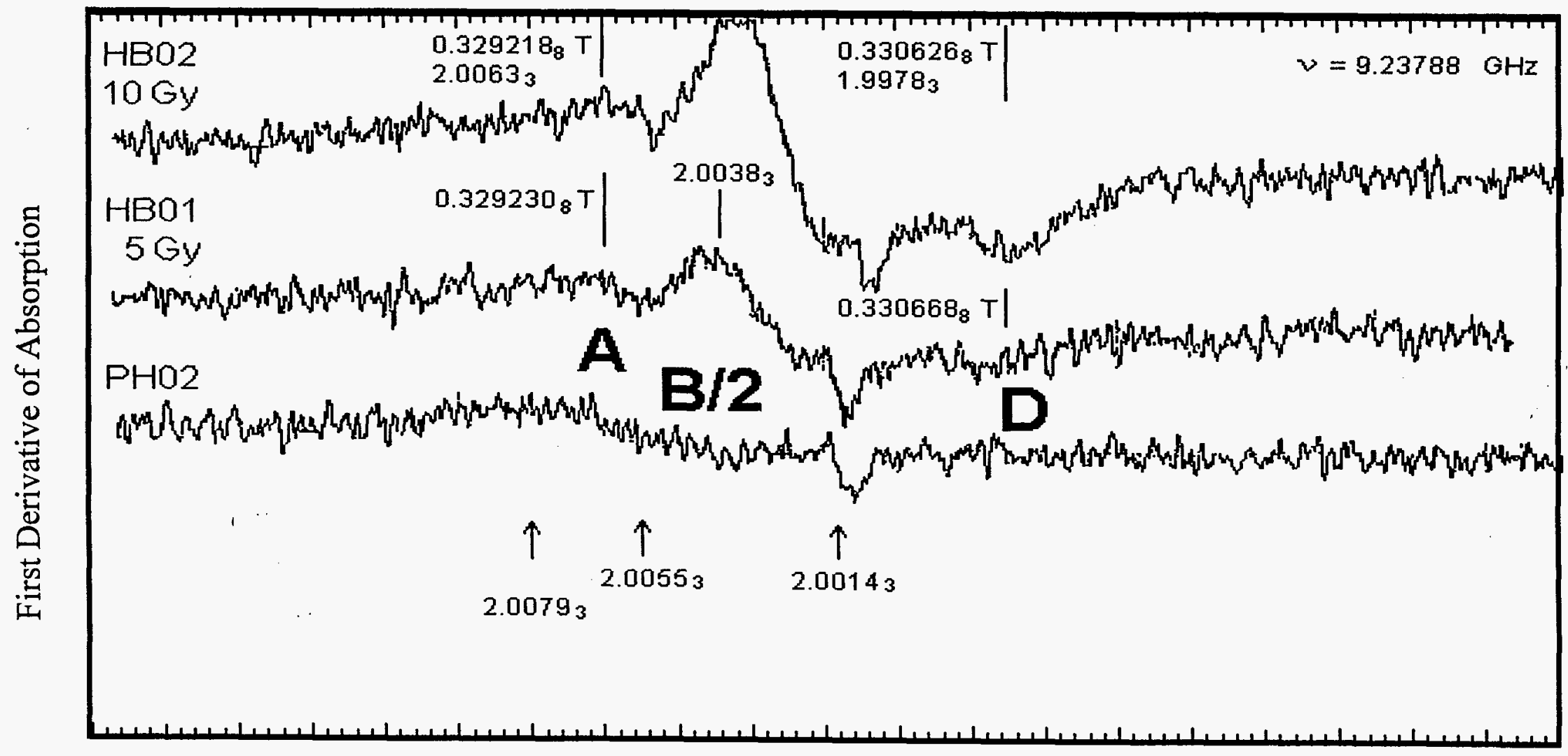

\section{Magnetic Field (tesla, T)}

Figure 3. EPR spectra showing the growth of radiation-sensitive components in samples with 0 Gy, 5 Gy, and 10 Gy nominal added dose. ' $A$ ', 'B/2', and ' $D$ ' are the spectral regions identified in this study, as discussed in the text. 


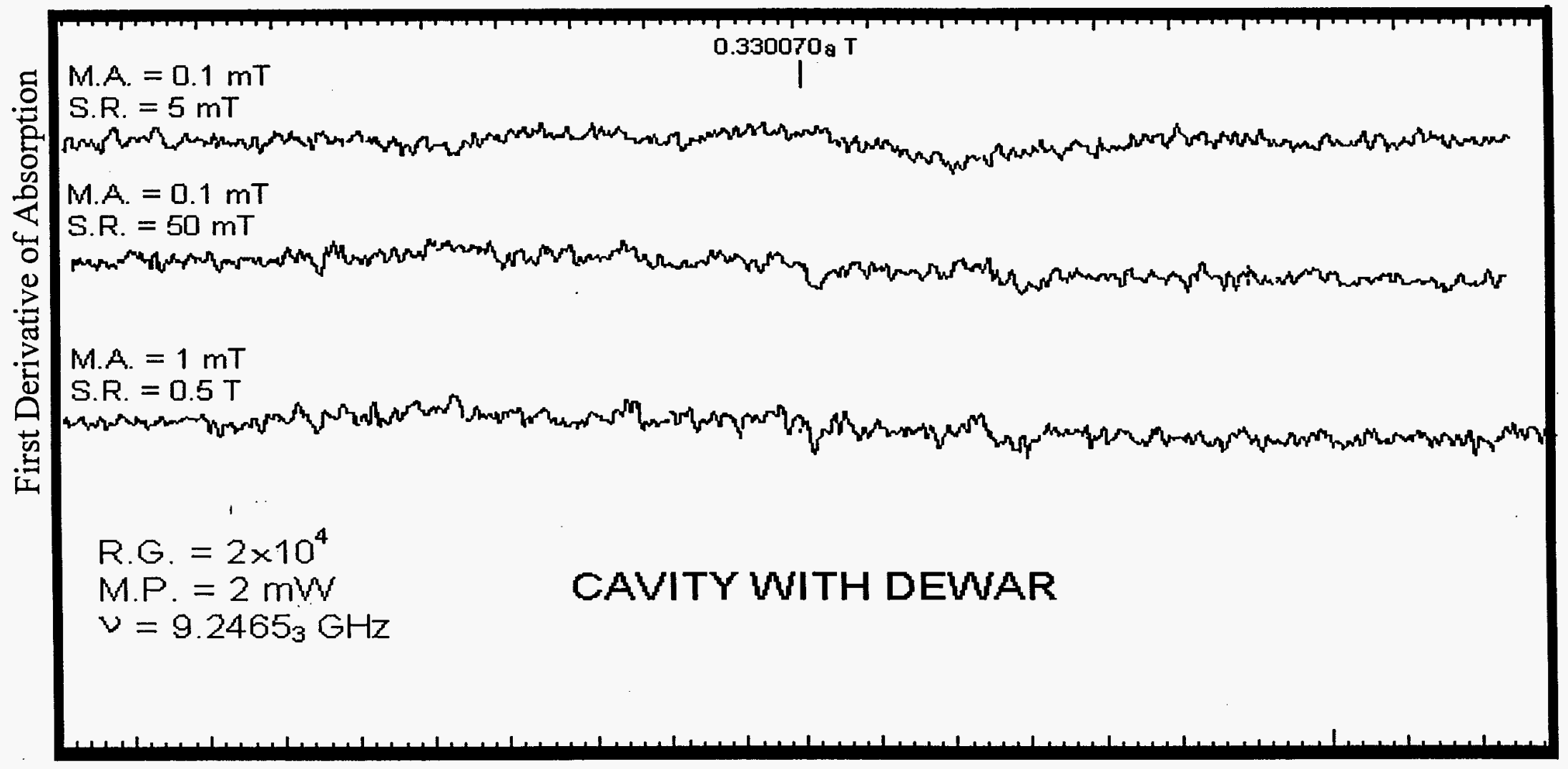

\section{Magnetic Field (tesla, T)}

Figure 4. EPR spectra of the empty microwave cavity (for comparison with Fig. 5). 


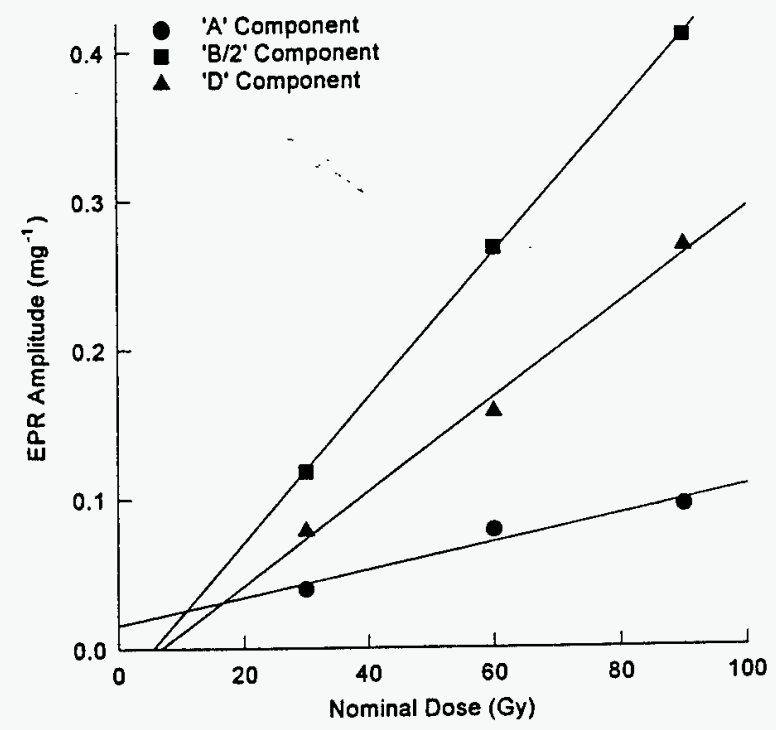

Figure 5. Linear regression of EPR spectral component response with dose for Sample HB09

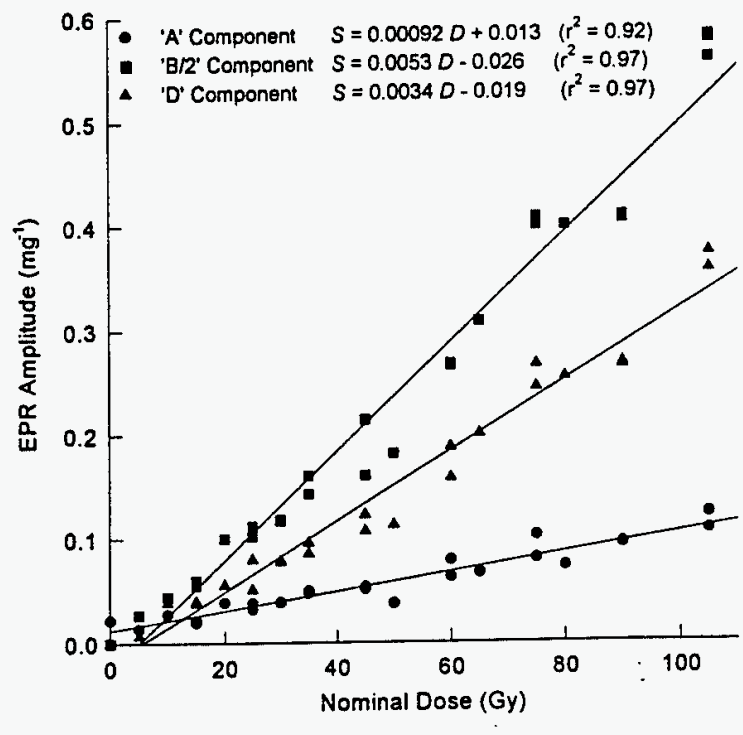

Figure 6. Linear regression of EPR spectral component response with dose for all samples 


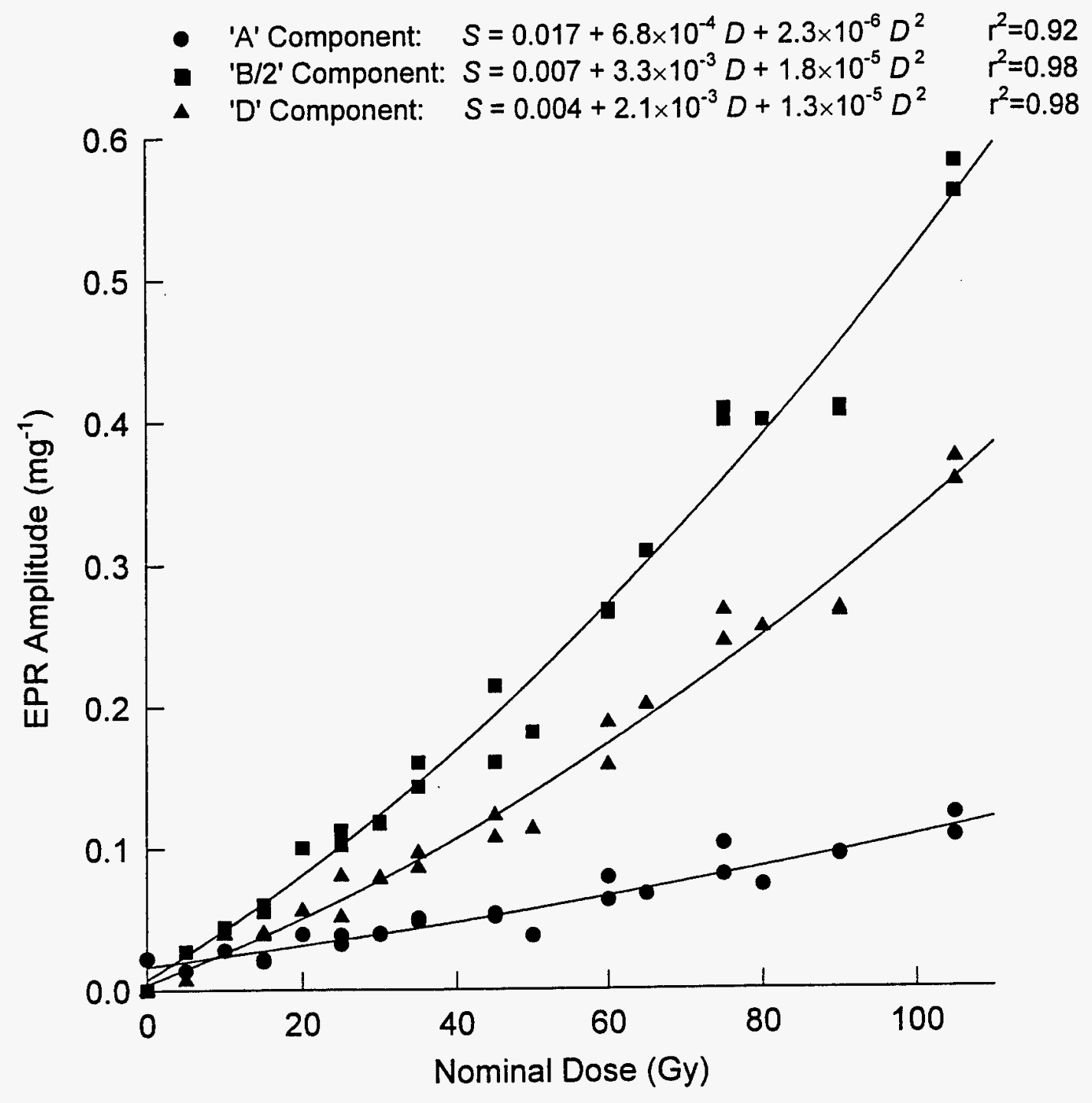

Figure 7. Quadratic fits to the EPR data (all samples). 


\section{ACKNOWLEDGEMENTS}

The authors wish to acknowledge the assistance of Larry N. Stillwell (Indiana Purdue University, Ft. Wayne) and Robert Jeske (University of Wisconsin, Madison), who provided the teeth and contextual materials for this work. Debbie A. Roberts and Michael E. Murray of the Oak Ridge National Laboratory Life Sciences Division determined by gamma spectrometry the activity concentrations of radioisotopes reported here. 


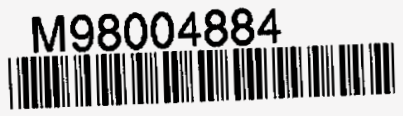

Report Number (14) ORNL/CP- -97381
CONE-980363--

Publ. Date (11) 199803

Sponsor Code (18) DOE/ CR,XF

UC Category (19) UC-900, DOE/ER 